\title{
Impact of anti-thymocyte globulin dose for graft-versus-host disease prophylaxis in allogeneic hematopoietic cell transplantation from matched unrelated donors: a multicenter experience
}

\author{
Sara Butera ${ }^{1,2}$ - Marco Cerrano ${ }^{3}$ - Lucia Brunello ${ }^{1,4}$. Chiara Maria Dellacasa ${ }^{1}$ - Danilo Giuseppe Faraci ${ }^{1,2}$. \\ Sara Vassallo ${ }^{1,2}$. Nicola Mordini ${ }^{5}$ - Roberto Sorasio ${ }^{5}$ - Francesco Zallio ${ }^{4}$ - Alessandro Busca ${ }^{1}$ • Benedetto Bruno ${ }^{1,2}$. \\ Luisa Giaccone ${ }^{1,2}$
}

Received: 5 November 2020 / Accepted: 8 April 2021 / Published online: 4 May 2021

(C) The Author(s) 2021

\begin{abstract}
Despite the widespread use of rabbit anti-thymocyte globulin (ATG) to prevent acute and chronic graft-versus-host disease (aGVHD, cGVHD) after allogeneic hematopoietic cell transplantation (allo-HCT), convincing evidence about an optimal dose is lacking. We retrospectively evaluated the clinical impact of two different ATG doses (5 vs 6-7.5 mg/kg) in 395 adult patients undergoing HSCT from matched unrelated donors (MUD) at 3 Italian centers. Cumulative incidence of aGVHD and moderatesevere cGVHD did not differ in the 2 groups. We observed a trend toward prolonged overall survival (OS) and disease-free survival (DFS) with lower ATG dose (5-year OS and DFS $56.6 \%$ vs. $46.3 \%, p=0.052$, and $46.8 \%$ vs. $38.6 \%, p=0.051$, respectively) and no differences in relapse incidence and non-relapse mortality. However, a significantly increased infectionrelated mortality (IRM) was observed in patients who received a higher ATG dose (16.7\% vs. $8.8 \%$ in the lower ATG group, $p=0.019$ ). Besides, graft and relapse-free survival (GRFS) was superior in the lower ATG group (5-year GRFS $43.1 \%$ vs. $32.4 \%$, $p=0.014)$. The negative impact of higher ATG dose on IRM and GRFS was confirmed by multivariate analysis. Our results suggest that ATG doses higher than $5 \mathrm{mg} / \mathrm{kg}$ are not required for MUD allo-HCT and seem associated with worse outcomes.
\end{abstract}

Keywords Anti-thymocyte globulin $\cdot$ Hematopoietic stem cell transplantation $\cdot$ Matched unrelated donors $\cdot$ GvHD

\section{Introduction}

Allogeneic hematopoietic cell transplantation (allo-HCT) is potentially curative for many hematologic malignancies, and

Sara Butera and Marco Cerrano contributed equally to this work.

Luisa Giaccone

luisa.giaccone@unito.it

1 Department of Oncology, SSD Trapianto Allogenico di Cellule Staminali, A.O.U. Città della Salute e della Scienza di Torino, Via Genova 3, 10126 Torino, Italy

2 Department of Molecular Biotechnology and Health Sciences, Division of Hematology, University of Torino, Torino, Italy

3 Department of Oncology, Division of Hematology, A.O.U. Città della Salute e della Scienza di Torino, Torino, Italy

4 Department of Hematology, A.O. Santissimi Antonio e Biagio e C Arrigo, Alessandria, Italy

5 Division of Hematology, A.O. Santi Croce e Carle, Cuneo, Italy human leukocyte antigen (HLA)-matched unrelated donors (MUD) are valid alternatives for patients lacking a HLAmatched related donor (MRD). However, despite improvements in HLA matching techniques that allow a better donor selection, the use of unrelated donors remains associated with an increased risk of graft-versus-host disease (GVHD) [1, 2]. Over the past decades, GVHD prophylaxis strategies have significantly improved, due to the introduction of effective combinations of immunosuppressive agents [3-6]. These regimens have been relatively successful for acute GVHD prophylaxis (aGVHD) but failed to satisfactorily prevent chronic GVHD (cGVHD) [7]. Several prospective randomized trials and subsequent meta-analyses supported the efficacy of prophylactic in vivo T-cell depletion with rabbit anti-thymocyte globulin (ATG) to prevent both aGVHD and cGVHD [8-14]. However, the benefits in terms of prevention of GVHD did not translate into a survival improvement [15-17]. The use of ATG has been associated with delayed immune reconstitution, which might increase the risk of opportunistic infections and impair graft-versus-tumor responses [18]. 
Two rabbit ATG formulations are used in clinical practice, distinct for antibody quantity and specificity depending on immunization source [19], Jurkat T-cell line (ATLG; Grafalon, previously termed ATG Fresenius, Neovii Biotech, Lexington, MA) or human thymocytes (Thymoglobulin; Genzyme-Sanofi, Cambridge, MA). ATG dosing and formulation significantly differed across studies, and despite its widespread use, convincing evidence about the most appropriate dose is lacking [20]. The identification of the optimal dose of ATG is essential for a conscious use in the context of a tricky balance between prevention of GVHD and immune reconstitution.

While earlier studies employed relatively doses as high as $15 \mathrm{mg} / \mathrm{kg}$ (Thymoglobulin) [8], more recent reports suggested that lower doses might be more appropriate. Therefore, we performed a retrospective study to assess the impact of ATG doses in patients undergoing allo-HCT from MUD.

\section{Methods}

The current study was performed retrospectively in three Italian Transplant Centers. We included all consecutive adult patients who received allo-HCT for hematological malignancies from $8 / 8$ or $7 / 8$ HLA MUD between January 2005 and December 2016 treated with the ATG brand Thymoglobulin as part of the GVHD prophylaxis regimen.

Clinical data were extracted from electronic database and through electronic and paper charts. Data collected included recipient age, year of transplant and time from diagnosis to transplant, disease status at transplant, conditioning regimen, graft source (bone marrow (BM) or peripheral blood (PB)), donor and recipient sex, HLA matching, GVHD prophylaxis, and ATG dose.

Conditioning regimens were myeloablative (MAC) or reduced intensity (RIC) and defined according to published criteria [21]. The degree of HLA matching was evaluated considering HLA-A, HLA-B, HLA-C, and HLA-DRB1 typing by high-resolution molecular methods. Disease status at transplant was stratified as early or advanced as previously described [22-26].

The European Society for Blood and Marrow Transplantation (EBMT) score was retrospectively calculated according to published criteria [27].

The cut-off date for this analysis was October 2019.

\section{GVHD prophylaxis}

GVHD prophylaxis included cyclosporine (CSA) and shortcourse methotrexate (MTX, given intravenously on days 1, 3, 6 , and 11) or CSA combined with mycophenolate mofetil (MMF).

MTX day 11 dose could be omitted in case of toxicity.
ATG was administered at a total dose ranging from 5 to 7.5 $\mathrm{mg} / \mathrm{kg}$ body weight; the dose was chosen per physician's preference. ATG was administered at a dose of $2.5 \mathrm{mg} / \mathrm{kg}$ on day -3 and -2 or $0.5 \mathrm{mg} / \mathrm{kg}$ on day $-3,2 \mathrm{mg} / \mathrm{kg}$ on day -2 , and $2.5 \mathrm{mg} / \mathrm{kg}$ on day $-1(5 \mathrm{mg} / \mathrm{kg}$ total dose $) ; 2 \mathrm{mg} / \mathrm{kg}$ from day -3 to -1 ( $6 \mathrm{mg} / \mathrm{kg}$ total dose $) ; 3.5 \mathrm{mg} / \mathrm{kg}$ on day -3 and $-2(7 \mathrm{mg} / \mathrm{kg}$ total dose); and $3.75 \mathrm{mg} / \mathrm{kg}$ on day -3 and -2 (7.5 $\mathrm{mg} / \mathrm{kg}$ total dose).

\section{Supportive care}

Antifungal agents, mostly fluconazole, were routinely administered to all patients. During the neutropenic phase, patients received prophylactic quinolones or cephalosporins. Long-term cotrimoxazole prophylaxis against Pneumocystis jirovecii and antiviral prophylaxis with acyclovir were performed in all patients. Cytomegalovirus (CMV) reactivation was routinely monitored at least weekly by polymerase chain reaction (PCR) and/or antigenemia assay. CMV reactivation was pre-emptively treated with ganciclovir or valganciclovir after detection of 2 consecutive positive PCR assay results or 1 positive antigenemia assay in peripheral blood. All patients were weekly monitored for EpsteinBarr virus (EBV) reactivation by PCR in peripheral blood samples. In case of confirmed EBV reactivation, reduction of immunosuppression was performed if GVHD did not concurrently occur and the anti-CD20 monoclonal antibody rituximab was administered. All blood products were irradiated and leukocyte depleted.

\section{Study endpoints}

We aimed to assess whether lower ATG doses (i.e., 5 $\mathrm{mg} / \mathrm{kg}$ ) were equally effective as higher ones in MUD allo-HCT. Primary endpoints were cumulative incidence of aGVHD (grade II-IV and grade III-IV) and moderate/severe cGVHD. Acute GVHD was scored by Glucksberg criteria [28]. Severity of cGVHD was assessed according to the National Institutes of Health (NIH) criteria [29]. Relapse or death from any cause before the occurrence of GVHD were considered as competing events for the incidence of GVHD.

Secondary endpoints included time to neutrophil engraftment, OS, disease-free survival (DFS), refined GVHD/ relapse-free survival (GRFS), cumulative incidence of relapse (RI), non-relapse mortality (NRM), infection-related mortality (IRM), and cumulative incidence of CMV and EBV reactivation.

Time to neutrophil engraftment was calculated from transplant day until the first of 3 consecutive days with absolute neutrophil count $>500 / \mathrm{ul}$. OS was defined as the time from allo-HCT to death, regardless of the 
cause while DFS as the time from allo-HCT to relapse or death from any cause, whichever occurred first. Refined GRFS was defined as the absence of grade III-IV aGVHD, severe cGVHD, relapse, and death as defined by Ruggeri et al. [30] RI was defined as time from allo-HCT to relapse. NRM was defined as death in remission. NRM was regarded as a competing event for relapse and relapse as a competing event for NRM. IRM was defined as death with infection as the primary cause of death, considering as competing events for IRM relapse, GVHD, and other causes of death [31].

The cumulative incidence of CMV infection was estimated as an event of interest and death without CMV infection as a competing event. Death without EBV reactivation was a competing event for the cumulative incidence of EBV. Time to infection was calculated from transplant day until the day of first positive result. Follow-up for survival was censored when the patient was last verified to be alive. Patients who received more than one transplant were censored as alive at day of the subsequent transplant.

\section{Statistical analysis}

Variables are reported as medians and interquartile ranges (IQR) for continuous variables and as numbers and proportions for categorical ones, respectively. Fisher's exact and Mann-Whitney $U$ test were used to compare categorical and continuous variables, respectively.

Follow-up duration was calculated with the inverse method [32].

OS, DFS, and GRFS were estimated using the Kaplan-Meier method and compared using the log-rank test. Cumulative incidence functions were estimated using appropriate competing risks analyses and compared by Gray's test.

Multivariate analyses were performed using Cox proportional hazards models, followed by backward stepwise selection. The following clinical variables were tested as risk factors: age at allo-HCT, sex, disease status (active disease vs. complete remission), intensity of conditioning regimen (MAC vs. RIC), graft source (PB vs. BM), donor and recipient sex mismatch (female to male vs. other), HLA match (8/8 vs. $7 / 8$ ), and ATG dose (higher dose vs. lower dose).

The proportional hazard (PH) assumption was validated by visual inspection and testing of Schöenfeld residuals [33]. Variance inflation factor (VIF) was used to rule out multicollinearity considering VIF $>4$ as unacceptable [34].

All reported $p$ values were two-sided at the conventional 0.05 significance level. Confidence intervals were reported at a $95 \%$ level. Statistical analyses were performed using STATA 12.1 (Stata Corporation, College Station, Texas) and NCSS 11 Statistical Software (NCSS, LCC. Kaysville, UT, USA)

\section{Results}

\section{Patient characteristics}

Three hundred ninety-five patients (males 54.7\%) with a median age at allo-HCT of 51.4 years (IQR 40.8-59.8 years) were included. Baseline patient characteristics are summarized in Table 1.

One-hundred and ninety-seven patients (49.9\%) received ATG at total dose of $5 \mathrm{mg} / \mathrm{kg}$ (lower dose group) and $198(50.1 \%)$ a higher dose, ranging from 6 to 7.5 $\mathrm{mg} / \mathrm{kg}$ (higher dose group) (Supplementary Table 1). Patient's characteristics, including graft source (PB in over $80 \%$ of the cases), disease status at allo-HCT, and GVHD prophylaxis (mainly CSA and short MTX course), were equally distributed in both groups, although MTX day 11 dose was omitted more often in the higher ATG dose group (54.1 vs $30.4 \%, p<0.001$ ). Myeloablative conditioning regimens were used more frequently in the lower dose group $(78.2 \%$ vs. $54.0 \%, p<0.001)$, and a higher proportion of HLA mismatched transplants was found in the higher dose one ( $45.5 \%$ vs. $25.4 \%, p<0.001)$. In addition, there was a slight imbalance of age (median age at transplant 52.4 years vs. 50.4 years in the lower and higher ATG dose group, respectively, $p=0.043$ ).

Median follow-up was 81.5 months (IQR 50.2-119.3 months).

\section{Engraftment and GVHD}

Median time to neutrophil engraftment was 17 days (IQR 1420 days), without difference according to ATG dose $(p=0.85)$. Only one patient in the low-dose group and 3 patients in the high dose one failed to engraft.

Day 180 cumulative incidences of grade II-IV aGVHD and grade III-IV aGvHD were similar between the groups, $28.6 \%$ vs. $33.9 \%(p=0.18)$ and $10.2 \%$ vs. $13.7 \%(p=0.26)$, in the lower and higher dose groups, respectively (Fig. 1a). Likewise, 4-year moderate-severe cGVHD did not differ between ATG doses (17.4\% in the lower dose group vs. $20.3 \%$ in the higher dose group, $p=0.34$ ) (Fig. $1 \mathrm{~b}$ and Supplementary Table 2).

By multivariate analysis, the presence of a HLA-mismatch was the only factor with a significant impact on the cumulative incidence of II-IV aGVHD (sub-hazard ratio [sHR]= 1.64, 95\% CI 1.15-2.33, $p=0.006)$ and III-IV aGVHD $(\mathrm{sHR}=3.17,95 \%$ CI $1.76-5.70, p<0.001)$, regardless of ATG dose. Conversely, no independent predictive factor for moderate/severe cGVHD was identified, with female donors into male recipients reaching borderline significance $(p=0.052)$. Of note, mismatched donors did not significantly influence the risk of cGVHD $(p=0.35)$ (Table 2 and Supplementary Table 4). 
Table 1 Baseline patient, disease, and transplant characteristics

\begin{tabular}{|c|c|c|c|c|}
\hline & All & Lower dose group & Higher dose group & $p$ \\
\hline Patients & 395 & 197 & 198 & \\
\hline Age* & $51.4(20.7-69.4)$ & $52.4(20.7-69.4)$ & $50.4(20.7-66.8)$ & 0.043 \\
\hline Male sex & $216(54.7 \%)$ & $99(50.3 \%)$ & $117(59 \%)$ & 0.09 \\
\hline Hematological disease & & & & 0.13 \\
\hline ALL-B/ALL-T & $52(13.2 \%)$ & $23(11.7 \%)$ & $29(14.7 \%)$ & \\
\hline AML/MDS & $199(50.4 \%)$ & $111(56.3 \%)$ & $88(44.4 \%)$ & \\
\hline MPN & $33(8.3 \%)$ & $14(7.1 \%)$ & $19(9.6 \%)$ & \\
\hline LPD & $111(28.1 \%)$ & $49(24.9 \%)$ & $62(31.3 \%)$ & \\
\hline Disease status at allo-HCT & & & & 0.11 \\
\hline $\mathrm{CR}$ & $265(67.1 \%)$ & $140(71.1 \%)$ & $125(63.1 \%)$ & \\
\hline Active disease & $130(32.9 \%)$ & $57(28.9 \%)$ & $73(36.9 \%)$ & \\
\hline EBMT score & & & & 0.54 \\
\hline Low risk & $154(39 \%)$ & $82(41.8 \%)$ & $72(36.4 \%)$ & \\
\hline Intermediate & $93(23.5 \%)$ & $44(22 \%)$ & $49(24.7 \%)$ & \\
\hline High & $148(37.5 \%)$ & $71(36.2 \%)$ & $77(38.9 \%)$ & \\
\hline Conditioning regimen & & & & $<.001$ \\
\hline MAC & $258(65.3 \%)$ & $154(78.2 \%)$ & $107(54 \%)$ & \\
\hline RIC & $137(34.7 \%)$ & $43(21.8 \%)$ & $91(46 \%)$ & \\
\hline Stem cell source & & & & 0.56 \\
\hline $\mathrm{BM}$ & $55(13.9 \%)$ & $25(12.7 \%)$ & $30(15.15 \%)$ & \\
\hline $\mathrm{PB}$ & $340(86.1 \%)$ & $172(87.3 \%)$ & $168(84.85 \%)$ & \\
\hline GVHD prophylaxis & & & & 0.13 \\
\hline $\mathrm{CSA}+\mathrm{MTX}$ & $372(94.2 \%)$ & $190(96.5 \%)$ & $182(91.9 \%)$ & \\
\hline $\mathrm{CSA}+\mathrm{MMF}$ & $23(5.8 \%)$ & $7(3.5 \%)$ & $16(8.1 \%)$ & \\
\hline Female to male $\mathrm{D} / \mathrm{R}$ & $53(13.4 \%)$ & $25(12.7 \%)$ & $28(14.1 \%)$ & 0.77 \\
\hline HLA disparity & & & & $<.001$ \\
\hline No mismatch & $255(64.6 \%)$ & $147(74.6 \%)$ & $108(54.5 \%)$ & \\
\hline 1 HLA locus mismatch & $140(35.4 \%)$ & $50(25.4 \%)$ & $90(45.5 \%)$ & \\
\hline
\end{tabular}

Values in bold are significant $p$ values

*Median (range); otherwise, data are presented as number (\%). $A L L$ acute lymphoid leukemia, $A M L$ acute myeloid leukemia, $C R$ complete remission, $D / R$ donor/recipient, $L P D$ lymphoproliferative disorders, $M A C$ myeloablative conditioning, $M D S$ myelodysplastic syndrome, $M P N$ myeloproliferative neoplasms, $R I C$ reduced intensity conditioning, $B M$ bone marrow, $P B$ peripheral blood stem cells, $C S A$ ciclosporin, $M T X$ methotrexate, $M M F$ mycophenolate mofetil

\section{Survival outcomes}

Estimated median OS and DFS for the entire cohort were 77.3 months and 13.0 months, respectively, with a trend toward an advantage for low ATG dose compared to the higher one (5year OS $56.6 \%$ vs. $46.3 \%, p=0.052$, and 5-year DFS $46.8 \%$ vs. $38.6 \%, p=0.051$, respectively) (Fig. $2 \mathrm{a}-\mathrm{b}$ ). Both by univariate and by multivariate analysis, the only factor significantly associated with OS and DFS was disease status at allo-HCT $(\mathrm{HR}=2.13,95 \%$ CI $1.61-2.82, p<0.001$ and $\mathrm{HR}=2.38,95 \%$ CI $1.83-3.08, p<0.001$, respectively).

GRFS was significantly improved in the lower ATG dose group (5-year GRFS $43.1 \%$ vs. $32.4 \%$ in the higher dose group, $p=0.014$ ) (Fig. 2c). By multivariate analysis, higher dose of ATG remained significantly associated with a reduced GRFS (HR $=1.37,95 \%$ CI 1.06-1.78, $p=0.015$ ), along with active disease at transplant (HR=2.11, 95\% CI 1.61-2.76, $p<0.001)$. Conversely the use of RIC was associated with an improved GRFS (HR=0.72, 95\% CI 0.54-0.96, $p=0.023$ ) (Table 2 and Supplementary Table 4).

\section{Relapse incidence and non-relapse mortality}

Relapse risk did not differ according to ATG dose (5-year RI $31.7 \%$ and $33.6 \%$ in the lower and higher ATG dose group, respectively, $p=0.66$ ) (Fig. 2d). By multivariate analysis, only age and active disease had an impact on RI (sHR=0.98, 95\% CI $0.97-0.99, p<0.001$, and $\mathrm{sHR}=2.06,95 \%$ CI $1.46-2.92$, $p<0.001$, respectively).

Disease relapse was the most common cause of death in both groups, while the main causes of NRM were infections ( $N=18,46.1 \%$ vs. $N=34,60.7 \%, p=0.018)$, followed by organ 

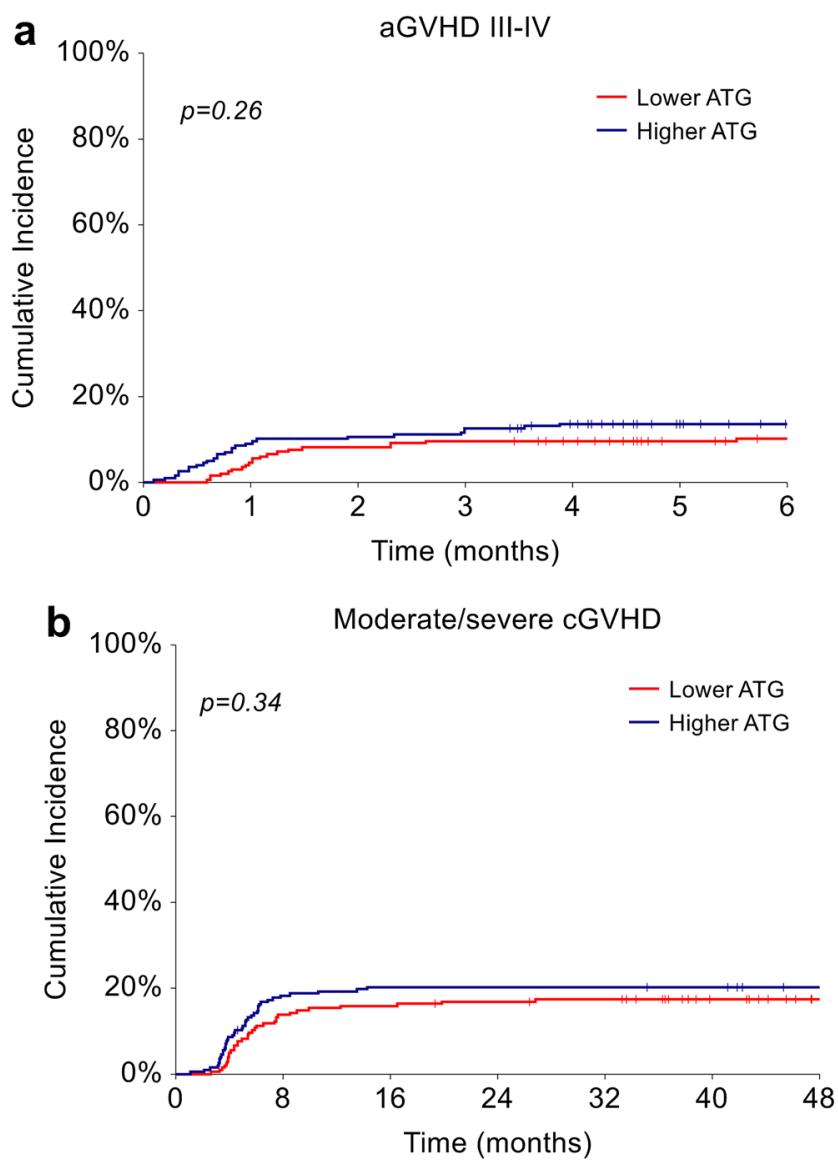

Fig. 1 Cumulative incidence of GVHD. (a) Cumulative incidence of aGVHD grades III to IV and (b) cumulative incidence of moderate to severe cGVHD in patients treated with lower dose $(5 \mathrm{mg} / \mathrm{kg})$ and higher dose $(6-7.5 \mathrm{mg} / \mathrm{kg})$ of ATG

failure $(N=12,30.8 \%$ vs. $N=13,23.2 \%, p=\mathrm{ns})$ and GVHD $(N=9,23.1 \%$ vs. $N=7,12.5 \%, p=$ ns) in the lower and higher ATG dose groups, respectively. Two patients who received higher ATG doses died from road accidents. Higher ATG dose was associated with a non-significant trend toward an increased NRM (5-year NRM 27.9\% vs. 21.5\%, $p=0.094$, Fig. 2e), which was significantly influenced by age and active disease at transplant $(\mathrm{sHR}=1.04,95 \%$ CI 1.02-1.06, $p<0.001$, and $\mathrm{sHR}=1.69,95 \%$ CI $1.14-2.50, p=0.01$, respectively) by multivariate analysis (Supplementary Table 4).

\section{Infection-related mortality and viral infections}

A statistically significantly higher probability of IRM was observed in patients who received a higher ATG dose (16.7\% vs. $8.8 \%, \mathrm{sHR}=2.01,95 \%$ CI 1.12-3.61, $p=0.019$, Fig. 2f). The adverse impact of higher ATG dose on IRM was confirmed by multivariate analysis $(\mathrm{sHR}=2.05,95 \% \mathrm{CI}$ $1.14-3.68, p=0.016)$, along with higher age $(\mathrm{sHR}=1.04,95 \%$ CI 1.02-1.07, $p=0.002$ ) and active disease at transplantation (sHR=2.46, 95\% CI 1.41-4.28, $p=0.002$ ) (Table 2).
Detailed data on CMV and EBV reactivations was missing in 47 patients. Day 100 cumulative incidence of CMV reactivation was $32.7 \%$ in lower ATG dose group and $35.6 \%$ in the higher dose group $(p=0.30)$. Median day of CMV reactivation was day 39 (IQR 29-48 days) in the lower dose group and day 30 in the higher dose group (IQR 21-43 days), without difference according to ATG dose $(p=0.22)$. EBV reactivation occurred in $10.7 \%$ patients in the lower ATG dose group and $11.1 \%$ in the higher dose one $(p=0.95)$. Pneumonia accounted for $15(28.8 \%)$ infection-related deaths, probable/proven invasive fungal infection for $17(32.7 \%)$, septic shock for 10 (19.2\%), central nervous system infection for $4(7.7 \%)$, and other/unknown infection for $6(11.6 \%)$. Causes of IRM according to ATG dose are summarized in Supplementary Table 5.

\section{Subgroup analyses}

Given the major impact of disease status at allo-HCT on clinical outcomes, we conducted a subgroup analysis on patients in remission at the time of transplant $(n=265)$. ATG dose did not impact on grade III-IV aGVHD $(p=0.34)$ and moderatesevere cGVHD $(p=0.67)$. Median OS was not reached in these patients and was negatively affected by higher ATG dose (5year OS $53.0 \%$ vs. $68.6 \%, \mathrm{HR}=1.58$, 95\% CI $1.08-2.32$, $p=0.018)$. Similarly, DFS was inferior with higher ATG dose (HR $=1.47,95 \%$ CI 1.04-2.1, $p=0.03)$, as well as GRFS $(\mathrm{HR}=1.51,95 \%$ CI 1.09-2.1, $p=0.013)$.

Next, we considered patients who received a RIC $(n=134)$, which was associated with a significantly higher probability of GRFS in our cohort. Higher ATG dose was detrimental in this subgroup of patients in terms of GRFS (5-year GRFS $30.7 \%$ vs. $50.6 \%, \mathrm{HR}=1.85,95 \%$ CI 1.13-3.04, $p=0.013)$. Median OS of patients who received a RIC was 45.7 months, without difference according to ATG dose $(p=0.11)$.

Finally, we explored the role of ATG dose in HLAmatched patients $(n=255)$, but we did not find a significant impact on any outcome, while in the subgroup of HLAmismatched transplants $(n=140)$, a trend toward a better DFS, GRFS, and IRM was observed in patients receiving a lower ATG dose.

The impact of ATG dose on different clinical outcomes in the most relevant subgroups is summarized in Fig. 3 and Supplementary Figure 1 to 3.

\section{Discussion}

ATG showed to be protective against GVHD, and it is recommended as part of GVHD prophylaxis both in MUD and MRD transplants [35]. However, the determination of the optimal dose may be difficult, given the complex interplay of factors that have an impact on the risk of complications after 
allo-HCT. Indeed, when selecting the dose of ATG, both transplant-related factors including graft source, donor and conditioning regimen intensity, and disease-related factors should be balanced.

Recently, a consensus-based recommendation by an international expert panel suggested the use of $30 \mathrm{mg} / \mathrm{kg}$ and 60 $\mathrm{mg} / \mathrm{kg}$ of ATLG for sibling and unrelated MAC transplants, respectively, or $4.5-7.5 \mathrm{mg} / \mathrm{kg}$ of ATG [36].

In the randomized trial conducted by Finke et al., the addition of ATLG was associated with reduced extensive cGVHD, improved GRFS, and survival free of immunosuppressive therapy compared to standard prophylaxis, with no effect on relapse mortality and survival [37]. Of note, similar results were found by Kroger et al. in patients receiving MRD transplants with PB as graft source. The probability of CSA discontinuation at 1 year was $39 \%$ in the standard group and $91 \%$ in the ALTG group [11]. Even though the data observed for the available brands of ATG are difficult to compare because of their different immunologic and pharmacokinetics (PK) properties [38], the addition of ATG as GVHD prophylaxis showed similar results in cGVHD prevention and improvement of GRFS $[35,36]$.

Indeed, our study was limited by its retrospective nature and by the heterogeneous populations in terms of disease characteristics and transplantation modalities. However, we included a relatively large patient number with a rather long follow-up, which allowed a reliable estimation of ATG effects on long-term clinical outcomes at our centers. The two ATG dose groups showed some imbalances that were, however, adjusted by multivariate and subgroup analyses. MTX day 11 dose was omitted more often in the higher ATG dose group, but it did not exert an impact on any of the clinical outcome analyzed. Furthermore, the heterogeneity of high dose group did not translate into significant differences on key clinical outcomes in patients receiving 6,7 , or 7.5 $\mathrm{mg} / \mathrm{kg}$ of ATG (data not shown).

Overall, ATG dose did not appear to impact on aGVHD (any grade) and moderate-severe cGVHD. With the limitation of different ATG brands, these results are similar to those reported in the randomized trial by Walker et al. and in the extended follow-up by Finke et al. with ATLG [37, 39, 40].

Despite the use of ATG, HLA mismatch remained the only independent risk factor for the development of grade II-IV and severe aGVHD, which was not overcome by higher ATG doses. By contrast, both doses of ATG overcame the negative impact of HLA disparity on cGVHD. The complex immunological properties of ATG could explain the reduction of cGVHD risk. As a matter of fact, in addition to extensive Tcell depletion, ATG affects different immune effectors involved in cGVHD development, such as B lymphocytes and dendritic cells. Moreover, ATG was shown to induce regulatory T lymphocyte expansion $[41,42]$. 

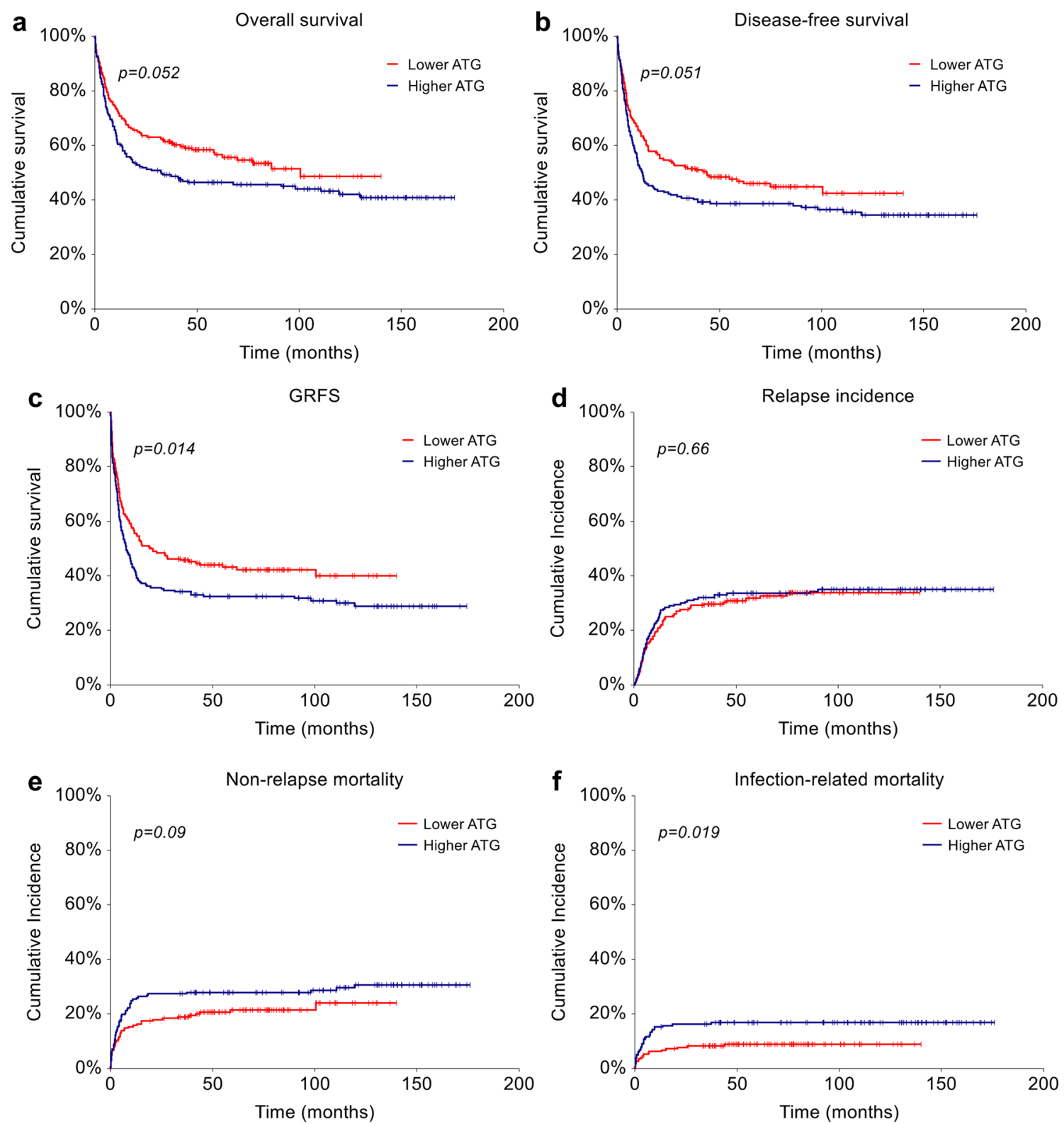

Fig. 2 Impact of ATG dose on transplant outcomes. (a) OS, (b) DFS, (c) GRFS, (d) RI, (e) NRM, and (f) IRM in patients treated with lower dose (5 $\mathrm{mg} / \mathrm{kg})$ and higher dose $(6-7.5 \mathrm{mg} / \mathrm{kg})$ of ATG

Data from the randomized study by Soiffer et al. hinted at a decreased progression-free survival and OS in patients receiving in vivo T-cell depletion [43], but this finding was not confirmed by other randomized studies [8-12]. In our analysis, higher ATG dose appeared to impair DFS and OS, particularly in the subgroup of patients in complete remission at allo-HCT.

Infectious complications remain a major concern associated with T-cell depletion; in particular, higher ATG dose (15 $\mathrm{mg} / \mathrm{kg}$ ) has been associated with an increased risk of lethal infections [8]. Similarly, in our cohort, higher ATG dose conferred an increased risk of infectious death, independently from other known prognostic factors.
In our study, although GVHD incidence did not significantly differ in the two groups, lower ATG dose was associated with a significantly improved GRFS, which was confirmed by multivariate analysis. This finding is noteworthy, because GRFS identifies patients who survive without relapse or severe complications and who may enjoy a high quality of life. The improvement on the composite outcome of GRFS in the lower ATG dose group was probably driven by the reduction of IRM, but a meaningful albeit not statistically significant reduction of GVHD ad relapses could have contributed to explaining this result.

The impact of ATG on clinical outcomes might also be affected by the intensity of conditioning regimen [44, 45]. 
a

Overall survival

Haz. Ratio

$(95 \% \mathrm{Cl})$

Subgroup No. pts

$1.02(1.00,1.75)$

\begin{tabular}{lr}
\multicolumn{2}{r}{ ALL PATIENTS } \\
\multicolumn{3}{c}{395} \\
SEX \\
Female & 179 \\
Male & 216 \\
& \\
HLA & MATCH \\
8/8 & 255 \\
7/8 & 140
\end{tabular}

DISEASE STATUS

CR 265

Active 130

CONDITIONING REGIMEN

MAC 261

RIC 134

GRAFT SOURCE

PB $\quad 340$

D/R SEX MISMATCH

Other 342

$\mathrm{F}$ to $\mathrm{M} \quad 53$

AGE

$<50$ years 210

$>50$ years 185

\begin{tabular}{c|}
\hline .0625 \\
1
\end{tabular}

Higher ATG better
$1.32(1.00,1.75)$

$1.16(0.76,1.76)$

$1.48(1.00,2.18)$

$1.20(0.83,1.73)$

$1.42(0.87,2.32)$

$1.58(1.08,2.32)$

$0.90(0.59,1.37)$

$1.22(0.86,1.74)$

$1.54(0.90,2.63)$

$1.30(0.96,1.75)$

$1.61(0.68,3.82)$

$1.13(0.84,1.53)$

$4.49(1.67,12.09)$

$1.20(0.82,1.75)$

$1.52(0.99,2.33)$

Lower ATG better c

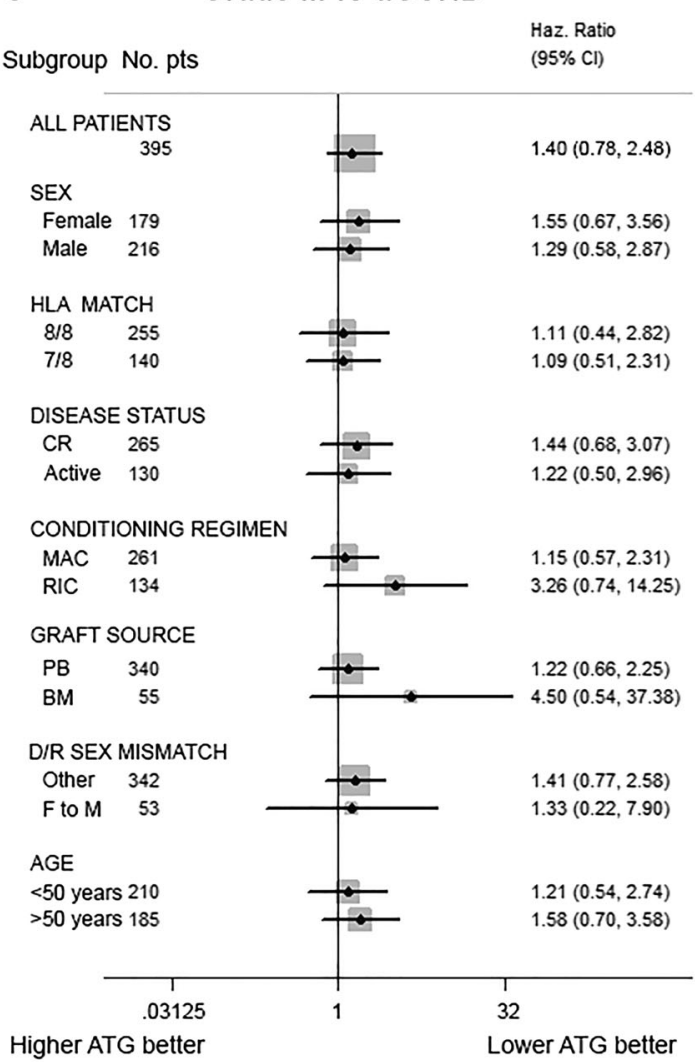

b

Subgroup No. pts

GRFS

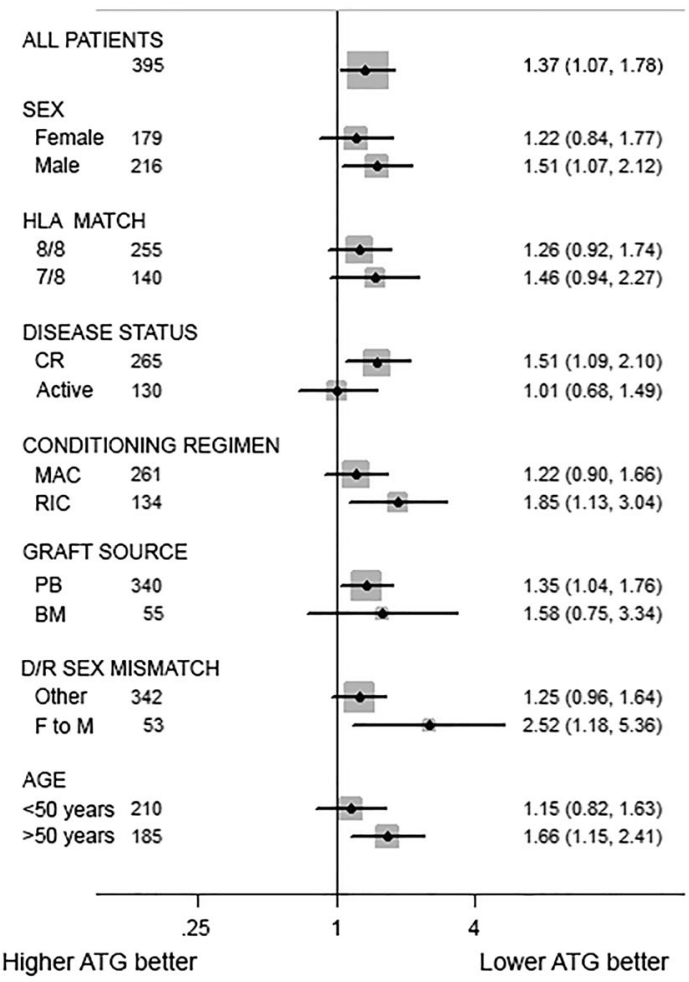

d Moderate-Severe cGVHD

\begin{tabular}{cr} 
Subgroup & No. pt \\
\cline { 2 - 2 } ALL PATIENTS \\
\multicolumn{3}{c}{395} \\
SEX & \\
Female & 179 \\
Male & 216
\end{tabular}

Haz. Ratio

(95\% Cl)

HLA MATCH

$\begin{array}{ll}8 / 8 & 255 \\ 7 / 8 & 140\end{array}$

DISEASE STATUS

CR 265

Active 130

CONDITIONING REGIMEN

MAC 261

RIC 134

GRAFT SOURCE

PB 34

BM 55

55

DIR SEX MISMATC

Other 342

$\mathrm{F}$ to $\mathrm{M} \quad 53$

AGE

$<50$ years 210

$>50$ years 185

$1.25(0.79,1.98)$

$1.37(0.66,2.83)$

$1.12(0.63,2.00)$

$1.48(0.83,2.65)$

$0.85(0.41,1.75)$

$1.12(0.67,1.88)$

$2.13(0.76,5.96)$

$1.16(0.68,1.98)$

$2.88(0.86,9.68)$

$1.42(0.87,2.31)$

$0.54(0.15,1.92)$

$1.50(0.90,2.50)$

$0.53(0.19,1.49)$

$1.07(0.59,1.94)$

$1.56(0.77,3.18)$

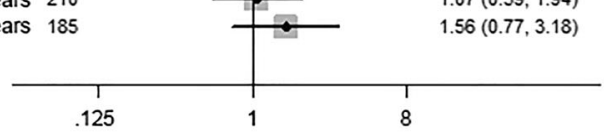

Higher ATG better 
Fig. 3 Subgroup analyses. Impact of ATG dose on (a) OS, (b) GRFS, (c) grade III-IV aGVHD, and (d) moderate/severe cGVHD according to baseline patients' characteristics

The role of ATG in RIC regimens remains to be determined, as only one randomized trial included RIC transplants and conflicting results were reported in retrospective studies [36, 39]. However, it was recommended that ATG should be considered in this setting as well, although a higher risk of relapse should be taken into account [36]. In our study, the use of RIC regimens correlated with improved GRFS, and the impact of ATG doses on clinical outcomes were consistent with those observed in the entire population. Feasibility and efficacy are in line with results observed in previous retrospective comparative studies [46].

Our results obtained with Thymoglobulin cannot be easily applied and generalized to different brands of ATG; nevertheless, nonrandomized comparison between standard dose and a lower dose of ATLG showed similar outcomes [47]. To improve the use of ATG in the future, a standard dose per body weight could be replaced by an individualized approach to ATG dosing based on PK and pharmacodynamic (PD) models. Admiraal et al. showed that PK of ATG was dependent on recipient's absolute lymphocyte count at time of infusion and cellular-target dosing provided an optimal ATG area under curve that resulted in lower incidence of GvHD and graft failure, while higher exposure led to worse immune reconstitution [48]. Prospective randomized trials are essential to develop and validate PK-based models $[49,50]$.

Recently, a matched-pair analysis of the Acute Leukemia Working Party of the EBMT compared the use of post-transplant cyclophosphamide (PTCy) versus ATG in the setting of 9/10 MMUD allo-HCT. A significantly lower incidence of severe aGVHD was observed with PTCy. The use of the latter was also associated with superior survival outcomes in terms of leukemiafree survival and GRFS [51]. A prospective GITMO study (NCT03270748) is currently investigating the efficacy of PTCy in 9/10 MMUD transplants for acute myeloid leukemia and myelodysplastic syndrome, and results are eagerly awaited.

In conclusion, in our study, an ATG dose of $5 \mathrm{mg} / \mathrm{kg}$ was as effective as higher doses for GVHD prevention after MUD allo-HCT. A higher dose did not confer any additional benefit; conversely it appeared to be associated with increased IRM and reduced GRFS. ATG doses and preferable T-cell depletion approaches should be addressed in prospective randomized studies.

Supplementary Information The online version contains supplementary material available at https://doi.org/10.1007/s00277-021-04521-z.
Acknowledgements We are indebted to the patients who participated in this study and all physicians, nurses, and support personnel for their care.

Author contribution B.B and L.G designed the study. S.B., M.C., L.G., and B.B. wrote the report. S.B., M.C., and L.G. supervised the clinical conduction of the study and data analysis. A.B, B.B., C.D., L.G., N.M., and F.Z. supervised the data collection, analyzed the data, and reviewed and assisted in writing the manuscript. A.B., B.B., L.B., C.D., D.F., L.G., R.S., and S.V. recruited the patients. S.B. and M.C. performed statistical analyses.

Funding Open access funding provided by Università degli Studi di Torino within the CRUI-CARE Agreement.

Data Availability Data is available upon reasonable request to the corresponding author.

\section{Declarations}

Statement of human rights All procedures performed were in accordance with the ethical standards of the institutional and national research committee and with the 1964 Helsinki declaration and its later amendments or comparable ethical standards. The study was approved by the local Institutional Review Board.

Consent to participate Informed consent was obtained from all individual participants included in the study.

Conflict of interest The authors declare no competing interests. Open Access This article is licensed under a Creative Commons Attribution 4.0 International License, which permits use, sharing, adaptation, distribution and reproduction in any medium or format, as long as you give appropriate credit to the original author(s) and the source, provide a link to the Creative Commons licence, and indicate if changes were made. The images or other third party material in this article are included in the article's Creative Commons licence, unless indicated otherwise in a credit line to the material. If material is not included in the article's Creative Commons licence and your intended use is not permitted by statutory regulation or exceeds the permitted use, you will need to obtain permission directly from the copyright holder. To view a copy of this licence, visit http://creativecommons.org/licenses/by/4.0/.

\section{References}

1. Tiercy JM (2016) How to select the best available related or unrelated donor of hematopoietic stem cells? Haematologica. 101:680 687

2. Lee SJ, Klein J, Haagenson M, Baxter-Lowe LA, Confer DL, Eapen M, Fernandez-Vina M, Flomenberg N, Horowitz M, Hurley CK, Noreen H, Oudshoorn M, Petersdorf E, Setterholm M, Spellman S, Weisdorf D, Williams TM, Anasetti C (2007) High-resolution donor-recipient HLA matching contributes to the success of unrelated donor marrow transplantation. Blood. 110: 4576-4583

3. Storb R, Deeg HJ, Farewell V, Doney K, Appelbaum F, Beatty P, Bensinger W, Buckner CD, Clift R, Hansen J (1986) Marrow transplantation for severe aplastic anemia: methotrexate alone compared with a combination of methotrexate and cyclosporine for prevention of acute graft-versus-host disease. Blood. 68:119-125

4. Ringdén O, Klaesson S, Sundberg B, Ljungman P, Lönnqvist B, Persson U (1992) Decreased incidence of graft-versus-host disease and improved survival with methotrexate combined with 
cyclosporin compared with monotherapy in recipients of bone marrow from donors other than HLA identical siblings. Bone Marrow Transplant 9:19-25

5. Nash RA, Johnston L, Parker P, McCune JS, Storer B, Slattery JT, Furlong T, Anasetti C, Appelbaum FR, Lloid ME, Deeg HJ, Kiem HP, Martin PJ, Schubert MM, Witherspoon RP, Forman SJ, Blume KG, Storb R (2005) A phase I/II study of mycophenolate mofetil in combination with cyclosporine for prophylaxis of acute graftversus-host disease after myeloablative conditioning and allogeneic hematopoietic cell transplantation. Biol Blood Marrow Transpl 11: 495-505

6. Kharfan-Dabaja M, Mhaskar R, Reljic T, et al. (2014) Mycophenolate mofetil versus methotrexate for prevention of graft-versus-host disease in people receiving allogeneic hematopoietic stem cell transplantation. Cochrane Database Syst Rev CD010280

7. Ram R, Storb R (2013) Pharmacologic prophylaxis regimens for acute graft-versus-host disease: past, present and future. Leuk Lymphoma 54:1591-1601

8. Bacigalupo A, Lamparelli T, Bruzzi P, Guidi S, Alessandrino PE, di Bartolomeo P, Oneto R, Bruno B, Barbanti M, Sacchi N, van Lint MT, Bosi A, for Gruppo Italiano Trapianti Midollo Osseo (GITMO) (2001) Antithymocyte globulin for graft-versus-host disease prophylaxis in transplants from unrelated donors: 2 randomized studies from Gruppo Italiano Trapianti Midollo Osseo (GITMO). Blood. 98:2942-2947

9. Socie G, Schmoor C, Bethge WA et al (2011) Chronic graft-versushost disease: long-term results from a randomized trial on graftversus-host disease prophylaxis with or without anti-T-cell globulin ATG-Fresenius. Blood. 117:6375-6382

10. Finke J, Bethge WA, Schmoor C, Ottinger HD, Stelljes M, Zander AR, Volin L, Ruutu T, Heim DA, Schwerdtfeger R, Kolbe K, Mayer J, Maertens JA, Linkesch W, Holler E, Koza V, Bornhäuser M, Einsele H, Kolb HJ, Bertz H, Egger M, Grishina O, Socié G, ATG-Fresenius Trial Group (2009) Standard graftversus-host disease prophylaxis with or without anti-T-cell globulin in haematopoietic cell transplantation from matched unrelated donors: a randomised, open-label, multicentre phase 3 trial. Lancet Oncol 10:855-864

11. Kroger N, Solano C, Wolschke C et al (2016) Antilymphocyte globulin for prevention of chronic graft-versus-host disease. $\mathrm{N}$ Engl J Med 374:43-53

12. Walker I, Panzarella T, Couban S, Couture F, Devins G, Elemary M, Gallagher G, Kerr H, Kuruvilla J, Lee SJ, Moore J, Nevill T, Popradi G, Roy J, Schultz KR, Szwajcer D, Toze C, Foley R, Cell Therapy Transplant Canada (2020) Addition of anti-thymocyte globulin to standard graft-versus-host disease prophylaxis versus standard treatment alone in patients with haematological malignancies undergoing transplantation from unrelated donors: final analysis of a randomised, open-label, multicentre, phase 3 trial. Lancet Haematol 7:e100-e111

13. Yuan J, Pei R, Su W, Cao J, Lu Y (2017) Meta-analysis of the actions of antithymocyte globulin in patients undergoing allogeneic hematopoietic cell transplantation. Oncotarget. 8:10871-10882

14. Kumar A, Mhaskar AR, Reljic T, Mhaskar RS, Kharfan-Dabaja MA, Anasetti C, Mohty M, Djulbegovic B (2012) Antithymocyte globulin for acute-graft-versus-host-disease prophylaxis in patients undergoing allogeneic hematopoietic cell transplantation: a systematic review. Leukemia. 26:582-588

15. Bacigalupo A (2017) ATG in allogeneic stem cell transplantation: standard of care in 2017? Point. Blood Adv 1:569-572

16. Baron F (2017) Unrelated donor haemopoietic stem-cell transplantation: ATG or not? Lancet Haematol 4:e252-e253

17. Baron F, Galimard JE, Labopin M, Yakoub-Agha I, Niittyvuopio R, Kröger N, Griskevicius L, Wu D, Forcade E, Richard C, Aljurf M, Helbig G, Labussière-Wallet H, Mohty M, Nagler A (2020)
Allogeneic peripheral blood stem cell transplantation with antithymocyte globulin versus allogeneic bone marrow transplantation without anti-thymocyte globulin. Haematologica. 105:1138-1146

18. Kekre N, Antin JH (2017) ATG in allogeneic stem cell transplantation: standard of care in 2017? Counterpoint. Blood Adv 1:573576

19. Popow I, Leitner J, Grabmeier-Pfistershammer K et al (2013) A comprehensive and quantitative analysis of the major specificities in rabbit antithymocyte globulin preparations. Am J Transplant 13: 3103-3113

20. Shichijo T, Fuji S, Nagler A, Bazarbachi A, Mohty M, Savani BN (2020) Personalizing rabbit anti-thymocyte globulin therapy for prevention of graft-versus-host disease after allogeneic hematopoietic cell transplantation: is there an optimal dose? Bone Marrow Transplant 55:505-522

21. Gyurkocza B, Sandmaier BM (2014) Conditioning regimens for hematopoietic cell transplantation: one size does not fit all. Blood. 124:344-353

22. Cheson BD, Pfistner B, Juweid ME, Gascoyne RD, Specht L, Horning SJ, Coiffier B, Fisher RI, Hagenbeek A, Zucca E, Rosen ST, Stroobants S, Lister TA, Hoppe RT, Dreyling M, Tobinai K, Vose JM, Connors JM, Federico M, Diehl V, International Harmonization Project on Lymphoma (2007) Revised response criteria for malignant lymphoma. J Clin Oncol 25:579-586

23. Hallek M, Cheson BD, Catovsky D, Caligaris-Cappio F, Dighiero G, Döhner H, Hillmen P, Keating M, Montserrat E, Chiorazzi N, Stilgenbauer S, Rai KR, Byrd JC, Eichhorst B, O’Brien S, Robak T, Seymour JF, Kipps TJ (2018) iwCLL guidelines for diagnosis, indications for treatment, response assessment, and supportive management of CLL. Blood. 131:2745-2760

24. Platzbecker U, Fenaux P, Ades L et al (2019) Proposals for revised IWG 2018 hematological response criteria in patients with MDS included in clinical trials. Blood. 133:1020-1030

25. Dohner H, Estey E, Grimwade D et al (2017) Diagnosis and management of AML in adults: 2017 ELN recommendations from an international expert panel. Blood. 129:424-447

26. Bassan R, Hoelzer D (2011) Modern therapy of acute lymphoblastic leukemia. J Clin Oncol 29:532-543

27. Gratwohl A (2012) The EBMT risk score. Bone Marrow Transplant 47:749-756

28. Glucksberg H, Storb R, Fefer A et al (1974) Clinical manifestations of graft-versus-host disease in human recipients of marrow from HL-A-matched sibling donors. Transplantation. 18:295-304

29. Jagasia MH, Greinix HT, Arora M, Williams KM, Wolff D, Cowen EW, Palmer J, Weisdorf D, Treister NS, Cheng GS, Kerr H, Stratton P, Duarte RF, McDonald GB, Inamoto Y, Vigorito A, Arai S, Datiles MB, Jacobsohn D, Heller T, Kitko CL, Mitchell SA, Martin PJ, Shulman H, Wu RS, Cutler CS, Vogelsang GB, Lee SJ, Pavletic SZ, Flowers MED (2015) National Institutes of Health Consensus Development Project on Criteria for Clinical Trials in Chronic Graft-versus-Host Disease: I. The 2014 Diagnosis and Staging Working Group report. Biol Blood Marrow Transpl 21:389-401 e381

30. Ruggeri A, Labopin M, Ciceri F, Mohty M, Nagler A (2016) Definition of GvHD-free, relapse-free survival for registry-based studies: an ALWP-EBMT analysis on patients with AML in remission. Bone Marrow Transplant 51:610-611

31. Gratwohl A, Brand R, Frassoni F et al (2005) Cause of death after allogeneic haematopoietic stem cell transplantation (HSCT) in early leukaemias: an EBMT analysis of lethal infectious complications and changes over calendar time. Bone Marrow Transplant 36:757769

32. Korn EL (1986) Censoring distributions as a measure of follow-up in survival analysis. Stat Med 5:255-260

33. Grambsch PM, Therneau TM (1994) Proportional hazards tests and diagnostics based on weighted residuals. Biometrika. 81:515-526 
34. O'brien RM (2007) A caution regarding rules of thumb for variance inflation factors. Qual Quant 41:673-690

35. Penack O, Marchetti M, Ruutu T, Aljurf M, Bacigalupo A, Bonifazi F, Ciceri F, Cornelissen J, Malladi R, Duarte RF, Giebel S, Greinix H, Holler E, Lawitschka A, Mielke S, Mohty M, Arat M, Nagler A, Passweg J, Schoemans H, Socié G, Solano C, Vrhovac R, Zeiser R, Kröger N, Basak GW (2020) Prophylaxis and management of graft versus host disease after stem-cell transplantation for haematological malignancies: updated consensus recommendations of the European Society for Blood and Marrow Transplantation. Lancet Haematol 7:e157-e167

36. Bonifazi F, Rubio MT, Bacigalupo A, Boelens JJ, Finke J, Greinix H, Mohty M, Nagler A, Passweg J, Rambaldi A, Socie G, Solano C, Walker I, Barosi G, Kröger N (2020) Rabbit ATG/ATLG in preventing graft-versus-host disease after allogeneic stem cell transplantation: consensus-based recommendations by an international expert panel. Bone Marrow Transplant 55:1093-1102

37. Finke J, Schmoor C, Bethge WA et al (2015) Randomized trial on GvHD prophylaxis with or without Anti-Human T-Lymphocyte Immunoglobulin ATG-Fresenius (ATG-F) in allogeneic hematopoietic cell transplantation from matched unrelated donors: final long-term results after 8.6 years median follow-up. Blood 126: $853-853$

38. Oostenbrink LVE, Jol-van der Zijde CM, Kielsen K et al (2019) Differential elimination of anti-thymocyte globulin of fresenius and genzyme impacts T-cell reconstitution after hematopoietic stem cell transplantation. Front Immunol 10:315

39. Walker I, Panzarella T, Couban S, Couture F, Devins G, Elemary M, Gallagher G, Kerr H, Kuruvilla J, Lee SJ, Moore J, Nevill T, Popradi G, Roy J, Schultz KR, Szwajcer D, Toze C, Foley R, Canadian Blood and Marrow Transplant Group (2016) Pretreatment with anti-thymocyte globulin versus no antithymocyte globulin in patients with haematological malignancies undergoing haemopoietic cell transplantation from unrelated donors: a randomised, controlled, open-label, phase 3, multicentre trial. Lancet Oncol 17:164-173

40. Mohty M, Malard F (2017) Antithymocyte globulin for graftversus-host disease prophylaxis after allogeneic hematopoietic stem-cell transplantation. J Clin Oncol 35:3993-3995

41. Mohty M (2007) Mechanisms of action of antithymocyte globulin: T-cell depletion and beyond. Leukemia. 21:1387-1394

42. Feng X, Kajigaya S, Solomou EE, Keyvanfar K, Xu X, Raghavachari N, Munson PJ, Herndon TM, Chen J, Young NS (2008) Rabbit ATG but not horse ATG promotes expansion of functional CD4+CD25highFOXP3+ regulatory $\mathrm{T}$ cells in vitro. Blood. 111:3675-3683

43. Soiffer RJ, Lerademacher J, Ho V et al (2011) Impact of immune modulation with anti-T-cell antibodies on the outcome of reducedintensity allogeneic hematopoietic stem cell transplantation for hematologic malignancies. Blood. 117:6963-6970

44. Nagler A, Labopin M, Dholaria B, Niittyvuopio R, Maertens J, Poiré X, Cornelissen J, Reményi P, Bourhis JH, Beguin Y, Malladi R, Kerre T, Schroyens W, Savani BN, Mohty M (2019) Impact of antithymocyte globulin on outcomes of allogeneic hematopoietic cell transplantation with TBI. Blood Adv 3:1950-1960

45. Crocchiolo R, Esterni B, Castagna L, Fürst S, el-Cheikh J, Devillier R, Granata A, Oudin C, Calmels B, Chabannon C, Bouabdallah R, Vey N, Blaise D (2013) Two days of antithymocyte globulin are associated with a reduced incidence of acute and chronic graftversus-host disease in reduced-intensity conditioning transplantation for hematologic diseases. Cancer. 119:986-992

46. Devillier R, Crocchiolo R, Castagna L et al (2012) The increase from 2.5 to $5 \mathrm{mg} / \mathrm{kg}$ of rabbit anti-thymocyte-globulin dose in reduced intensity conditioning reduces acute and chronic GVHD for patients with myeloid malignancies undergoing allo-SCT. Bone Marrow Transplant 47:639-645

47. Ayuk F, Diyachenko G, Zabelina T, Wolschke C, Fehse B, Bacher U, Erttmann R, Kröger N, Zander AR (2008) Comparison of two doses of antithymocyte globulin in patients undergoing matched unrelated donor allogeneic stem cell transplantation. Biol Blood Marrow Transpl 14:913-919

48. Admiraal R, van Kesteren C, Jol-van der Zijde CM et al (2015) Association between anti-thymocyte globulin exposure and CD4+ immune reconstitution in paediatric haemopoietic cell transplantation: a multicentre, retrospective pharmacodynamic cohort analysis. Lancet Haematol 2:e194-e203

49. Boelens JJ, Admiraal R, Kuball J, Nierkens S (2018) Fine-tuning antithymocyte globulin dosing and harmonizing clinical trial design. J Clin Oncol 36:1175-1176

50. Mohty M, Malard F (2018) Reply to J.J. Boelens et al. J Clin Oncol 36:1177-1178

51. Battipaglia G, Labopin M, Kroger N et al (2019) Posttransplant cyclophosphamide vs antithymocyte globulin in HLAmismatched unrelated donor transplantation. Blood. 134:892-899

Publisher's note Springer Nature remains neutral with regard to jurisdictional claims in published maps and institutional affiliations. 